\title{
Complementary Split Ring Resonator Based Sensor for Crack Detection
}

\author{
Rajni *, Amanpreet Kaur **, Anupma Marwaha*** \\ *Associate Professor, Department of ECE, SBSSTC (PTU), Kapurthala, Punjab, India. \\ ** M. Tech., Research Scholar, Department of ECE, SBSSTC (PTU), Kapurthala, Punjab, India. \\ *** Associate Professor, Department of ECE, SLIET (Deemed University), Longowal, Punjab, India.
}

\section{Article Info \\ Article history: \\ Received Apr 22, 2015 \\ Revised Aug 13, 2015 \\ Accepted Aug 26, 2015}

\section{Keyword:}

Complementary

Crack detection

High frequency

Microstrip line

Split ring resonator

\begin{abstract}
In this paper, the performance of Complementary Split Ring Resonator (CSRR) based sensor is explored by varying the geometrical parameters of a sub millimeter crack. Behavior analysis of the CSRR based sensor is performed by variation in the parameters of crack. Variation in resonant frequency of sensor is observed in every case and is noteworthy for our purpose. This signifies the sensor's ability to detect crack of different geometrical parameters on a metal surface.The effectiveness of the sensor is being contemplated through this approach which is appreciable. An illustrious performance of the crack detection sensor has been discovered in this analysis. Simulated results show the feasibility of detecting very small cracks upto $25 \mu \mathrm{m}$ width, in the metallic surfaces.
\end{abstract}

Copyright (c) 2015 Institute of Advanced Engineering and Science. All rights reserved.

\section{Corresponding Author:}

Amanpreet Kaur,

Department of Electronics and Communication Engineering,

Punjab Technical University,

Kapurthala.

Email: amannatkaur@gmail.com

\section{INTRODUCTION}

Detection of irregularities such as crack was a critical issue earlier in all structural components that leads to failure of the system. In 1990's, near-field microwave and millimeter-wave techniques have been used extensively for detecting metal fatigue and assessing their various characteristics [1-3]. These techniques were employed to find the extent of corrosion precursor pitting and have distinguished credits over another standard technique like NDT, when identifying cracks in uncovered and covered surfaces. Moreover, they are reliable and cost effective techniques. In [4], open-ended waveguide sensor and dualbehavior resonator (DBR) filters were also propounded for detection of micro-cracks in metallic surfaces. However, these works had some limitations like low sensitivity and low operational frequency. So, a complementary split-ring resonator (CSRR) with a micro-strip line was used in [5] to detect cracks in metal surfaces as narrow as $100 \mu \mathrm{m}$ while operating around $5 \mathrm{GHz}$. A CSRR sensor is printed over ground plane of a microstrip line and printed circuit board technology was used for fabrication. Being sub-wavelength resonators, CSRR are very small than the traditional microstrip resonators. CSRR behaves as an electric dipole that can be excited by an axial electric field. CSRR geometery presented in [5] is also being used for finding defects in metallic surfaces, using a substrate integrated waveguide (SIW) as in [6].

Maximum metamaterial transmission lines have been accomplished by loading the host lines with series capacitances and shunt inductances (lumped or semi-lumped) [7-9]. However, artificial lines loaded with electrically small resonators, such as split-ring resonators (SRRs) also known as left-handed metamaterial [10-11] or CSRRs [12-13] are being registered and employed in the designing of antennas and novel microwave circuits [14-15]. 
Material reaction to electrodynamic fields is based on their electrical properties, like permeability, permittivity and conductivity. So, to observe changes in material Characterization of these properties are important. Material imperfections, such as submillimeter cracks in metallic, alter the electromagnetic nearfield distribution. This variation in the distribution of field (i.e. phase and magnitude) is an outcome of amendments in the medium effective essential specifications. These variations are used as an indication for the purpose of detecting crack, is the key element behind this crack detection mechanism employed in metal surfaces. Akin approach is being used to figure out defects in an aluminum plate.

In the presented work, a sensor based on single CSRR is used to detect small crack of various specification. The analysis of CSRR sensor is carried out by varying the parameters of crack. Here performance analysis of sensor is of prime concern. The same model has been use to detect $100 \mu \mathrm{m}$ crack previously, in this work cracks smaller than $100 \mu \mathrm{m}$ are considered that has not been analyzed with previous proposed structure. Examining the sensitivity of sensor to be able to detect cracks of different widths in micrometers and depths in millimeter is being encouraged here. In this paper, a background of the work done in the area explored is given in Section 1. Section 2 presents the design and working of CSRR based sensor. Section 3 gives results and analysis. Section 4 gives conclusion of paper.

\section{DESIGN AND WORKING OF CSRR BASED SENSOR}

CSRR are small structures having sub-wavelength resonant frequency. These structure exhibits resonant behavior due to the internal inductance and capacitance present in it, according to Pendry's work [16]. The CSRR has an equivalent LC resonant circuit and is used for miniaturiazation [17-18], multi-band operation [19], in wideband filters [20] and detection purpose. A single CSRR etched out from the ground plane of the microstrip line act as a crack detection sensor as shown in Figure 1. Electric field perpendicular to sensor surface stimulates the CSRR sensor in a similar way to most employed SRR structure which requires Magnetic field for excitation [21-22]. At resonance frequency of CSRR an appreciable enhancement in energy densities of electric and magnetic field around the resonator can be observed. The perturbance of the Field around resonator lead to a shift in the frequency and this shift depends on the material under test. The various integral parameters of the material are important for characterizing changes in the material leading to a variation in resonance frequency.

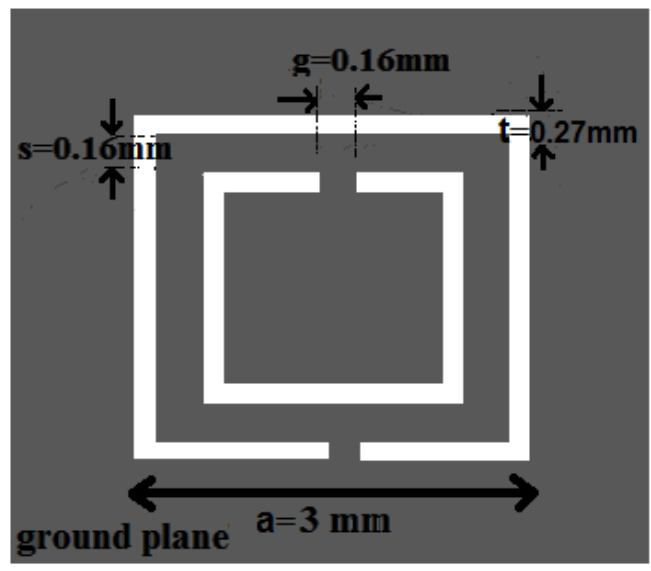

Figure 1 CSRR structure

In this proposed work, a variation in the resonant frequency is the indicator of the proper working of the sensor. Analyzing the performance of the sensor by varying the parameters of crack is main concern of this work. The sensor is designed by etching CSRR out from the ground of microstrip and is excited by a microstrip line as illustrated in Figure 2. This microstrip line act as a feeding element to the sensor. This has been used earlier as a stop band filter in [12]. Therefore it works in that frequency range where the transmission coefficient is minimum. A Rogers RO4350 substrate with a dielectric constant of 3.66, thickness of $0.75 \mathrm{~mm}$ a permittivity $\left(\varepsilon_{r}\right)$ of 3.66 , and a loss tangent $\delta$ of 0.0031 has been chosen for design of sensor with the width of the microstrip line equal to $1.68 \mathrm{~mm}$. It is well known that CSRR's dimensions depend on its resonant frequency. So, larger dimensions of CSRR assumes higher values of inductance and capacitance, thus lower is its resonant frequency. Dimensions of $\mathrm{a}=3 \mathrm{~mm}, \mathrm{~g}=\mathrm{s}=0.16 \mathrm{~mm}$ and $\mathrm{t}=0.27 \mathrm{~mm}$ 
are selected for the fabricated sensor. The sensor operates near around $5 \mathrm{GHz}$ when placed over aluminum plate covered by a layer of thin Teflon film with thickness of 0.0762 . Acquiring resonance at exact and particular frequency here is of least importance.

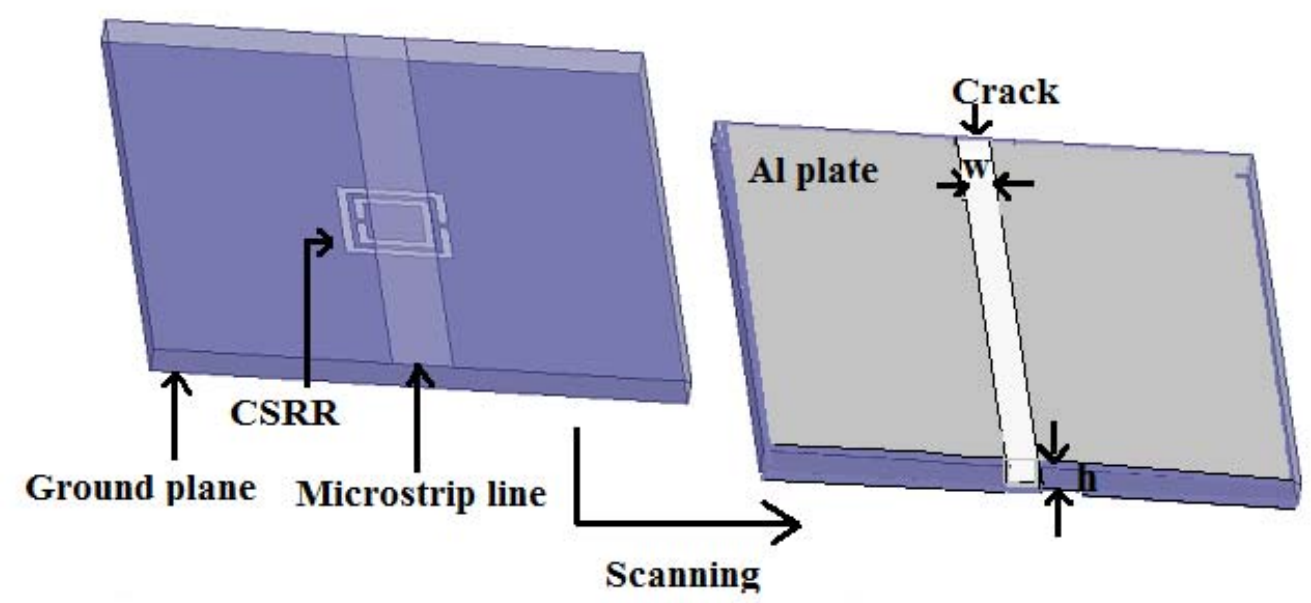

Figure 2. Scanning mechanism of sensor

\section{RESULTS AND DISCUSSION}

The geometrical parameters of crack like crack width (w) and crack height / depth (h) are varied to analyze the performance of the sensor. To test the potential of sensor to be able to detect cracks of various widths and depths we have considered several cases. Geometrical parameters of crack like width and depth are varied keeping one of these parameters constant at one time as discussed below. Any value in the range of sub-millimeter for crack width and in millimeter for crack depth can be chosen for testing the performance of sensor. So, in this work initially we have selected (i) a crack with width of $75 \mu \mathrm{m}$, keeping the width constant in this case and varying the depth of the crack from $1 \mathrm{~mm}$ to $1.5 \mathrm{~mm}$, then to $2 \mathrm{~mm}$ respectively. (ii) A crack with depth of $2 \mathrm{~mm}$ is kept fixed and various crack widths are considered measuring $25 \mu \mathrm{m}, 50 \mu \mathrm{m}$ and $75 \mu \mathrm{m}$. Secondly, analyses has also been carried out for the case when there is more than one crack on metal plate under test, considering two parallel cracks on the material surface. In this case analysis has been carried out by varying the separation distance between the cracks from $1 \mathrm{~mm}$ to $3 \mathrm{~mm}$ respectively.

\subsection{Performance Analysis of the Sensor by Varying Width and Depth of Crack}

i. Effect of crack depth of $1 \mathrm{~mm}, 1.5 \mathrm{~mm}$ and $2 \mathrm{~mm}$

Any anomalies in the material like cracks, lead to changes in the constituent properties of the material. These changes in the properties are very important in detection purposes. Such defects like small micrometer cracks influence the near field distribution of electromagnetic field. The disturbance of field around resonator causes a shift in the resonant frequency, which indicates the detection of crack by sensor. So, here we test the performance of the sensor by passing it over a defected aluminum plate having crack width of $75 \mu \mathrm{m}$ on it with $1 \mathrm{~mm}$ height of crack. During scanning it is observed that the near field around resonator is disturbed that clearly shows that sensor is able to detect crack of $75 \mu \mathrm{m}$ width and $1 \mathrm{~mm}$ height. Due to which the resonant frequency experience a downward shift as illustrated in Figure 3. Similarly, again for the same crack width of $75 \mu \mathrm{m}$, while changing the crack depth from $1 \mathrm{~mm}$ to $1.5 \mathrm{~mm}$, the scanning is done by moving the sensor over the metal surface and again a shift in resonance frequency towards lower range is noticed as shown in Figure 3. Further again keeping the crack width constant the depth is varied from $1.5 \mathrm{~mm}$ to $2 \mathrm{~mm}$ and similar results are registered. This analysis clearly depicts that the sensor is proficient enough to detect crack irrespective of the geometric variations in crack dimensions. 


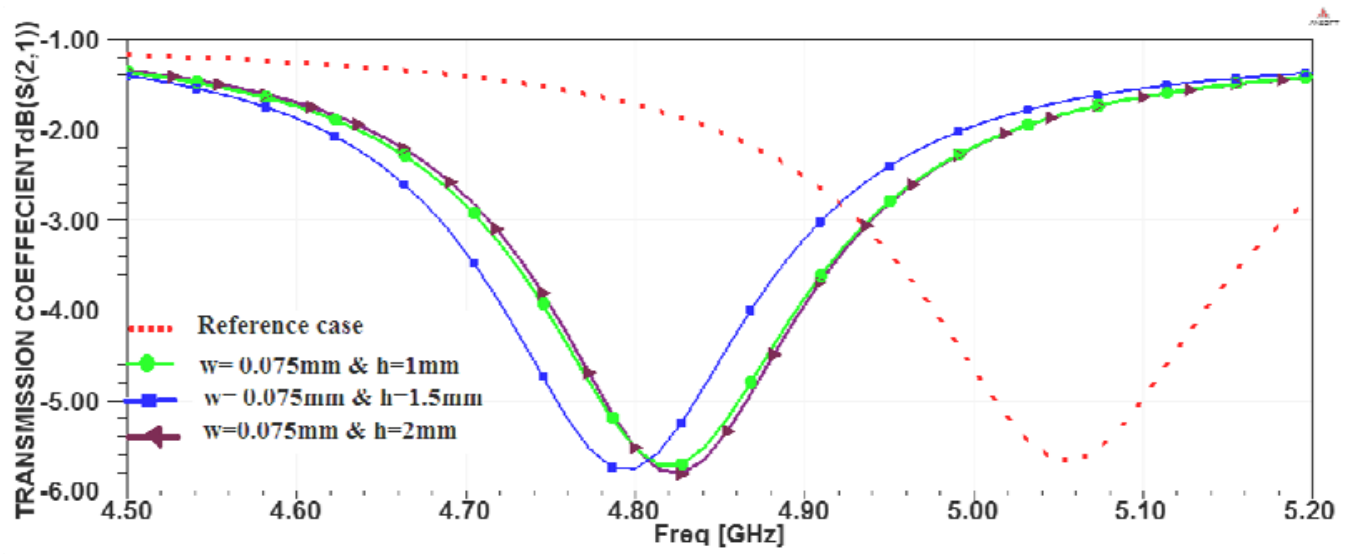

Figure 3. Transmission coefficient of the sensor for crack width of $75 \mu \mathrm{m}$ compared with aluminum plate, for crack depth of $1 \mathrm{~mm}, 1.5 \mathrm{~mm}$ and $2 \mathrm{~mm}$

ii. Effect of crack widths $25 \mu \mathrm{m}, 50 \mu \mathrm{m}$ and $75 \mu \mathrm{m}$.

In this case the crack depth is fixed to $2 \mathrm{~mm}$ and an analysis is done by varying the width of crack. The sensitivity of sensor towards a crack of different widths can be observed here. As a sensor is passed over a defected metal plate, a variation in the resonant frequency is observed when crack depth of $2 \mathrm{~mm}$ and width of $25 \mu \mathrm{m}$ is considered on the metal surface. Similar is observed when crack width is increased from $25 \mu \mathrm{m}$ to $50 \mu \mathrm{m}$. Further increasing the width from $50 \mu \mathrm{m}$ to $75 \mu \mathrm{m}$ of crack we again follow the same sensing mechanism and again a change is observed in the resonant frequency as shown in Figure 4. This variation shows that the sensor is able to detect cracks of different widths. It is investigated that even by increasing the crack width from 25 to $75 \mu \mathrm{m}$ the sensitivity of the sensor is still good. Thus the CSRR based sensor is capable of detecting cracks of different dimensions and is extremely appropriate for the purpose. This inexpensive technique of crack detection can be employed without any second thought and has a clear cut edge over other microwave techniques.

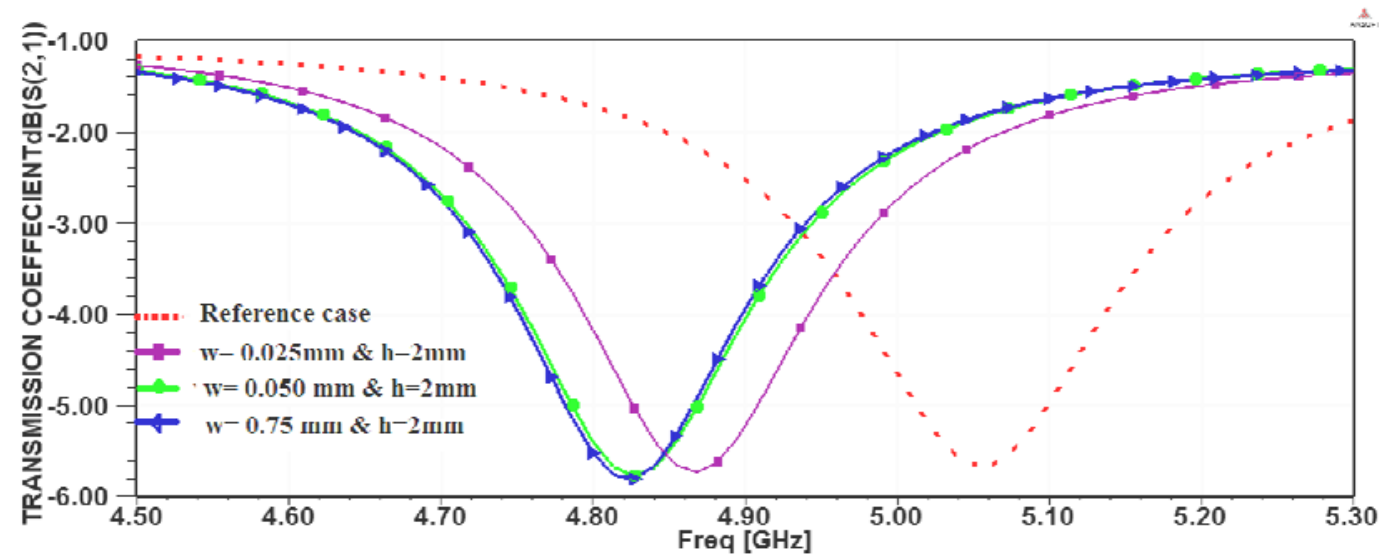

Figure 4. Transmission coefficient plot of sensor with crack depth of $2 \mathrm{~mm}$ compared with aluminum plate, for crack width of $25 \mu \mathrm{m}, 50 \mu \mathrm{m}$ and $75 \mu \mathrm{m}$

\subsection{Effect of Varying the Distance between Parallel Cracks}

We have considered different geometric parameters for crack in the above mentioned work and have seen that sensor is still able to detect cracks for both the cases in which either width of crack is increased to certain value or depth of crack is increased. A good performance by the sensor has been depicted in the work done so far. Investigating the performance of sensor by considering some different aspect for the crack is introduced. Furthermore, the performance of sensor is being examined by considering more than one crack on metal plate and varying the distance (d) between the parallel cracks. In this approach, for checking the 
effectiveness of sensor we have considered two parallel cracks on the aluminum plate having separation of $1 \mathrm{~mm}$ initially between them and are placed at equal distance from the center of plate. The senor is moved over this defected plate. The fields around the sensor get disturbed. So, the resonant frequency gets shifted towards left which is desirable. Similar is seen when the distance is increased from $1 \mathrm{~mm}$ to $2 \mathrm{~mm}$ and then after $2 \mathrm{~mm}$ to $3 \mathrm{~mm}$ as illustrated in Figure 5. So, this signifies that this sensor has the capacity to detect more than one crack on same metal surface and even can detect at different distance of separation between cracks.

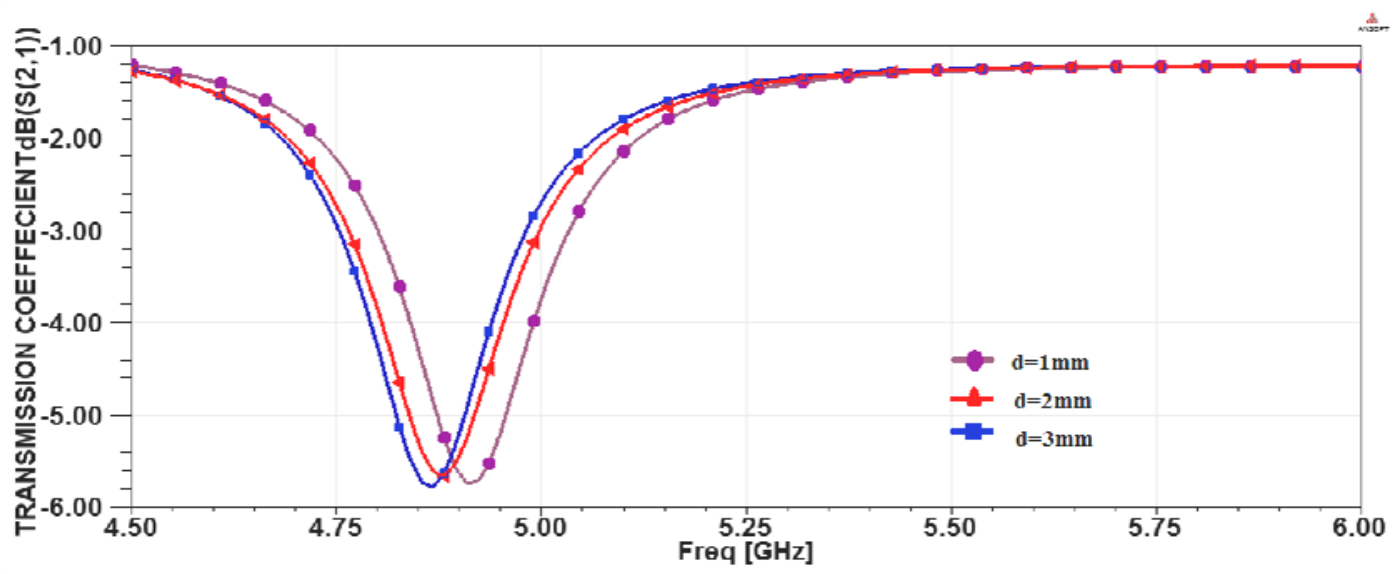

Figure 5. Transmission coefficient plot for the parallel placed crack at separation of $\mathrm{d}=1 \mathrm{~mm}, 2 \mathrm{~mm}$ and $3 \mathrm{~mm}$

\section{CONCLUSION}

The performance of the CSRR based sensor by varying geometric dimensions of crack has been analyzed and disclosed in this work. The proficiency of the sensor is contemplated by varying either crack width or crack height, keeping one parameter constant at a time and also by considering more than one crack on metal plate. This analysis explored that the downward shifting of resonant frequency in all the cases is an indicator of the ability of the sensor to detect crack of sub-millimeter dimensions upto $25 \mu \mathrm{m}$. Thus through this analysis we can say that a remarkable performance has been unveiled by the sensor. Essentially, the shifting of the resonant frequency reflects the effectiveness of the sensor and in turn is also a good evidence for this analysis.

\section{REFERENCES}

[1] R. Zoughi and S. Kharkovsky, "Microwave and millimeter wave sensors for crackdetection", Fatigue Fract. Eng. Mater. Struct., Vol. 31, No. 8, pp. 695-713, Aug. 2008.

[2] N. Qaddoumi, E. Ranu, and R. Zoughi, "Microwave detection of stress induced fatigue cracks in steel and potential of crack opening determination using a new phase sensitive approach based on a waveguide magic tee", in Review of Progress in Quantitative Nondestructice Evaluation, Vol. 18A, D. O. Thompson and D. E. Chimenti, Eds. New York: Kluwer, pp. 569-576, 1999.

[3] N. Qaddoumi, E. Ranu, J.D. Mc Colskey, R. Mirshahi, and R. Zoughi, "Microwave detection of stress-induced fatigue cracks in steel and potential for crack opening determination”, Res. Nondestruct. Eval., Vol. 12, No. 2, pp. 87-103, Oct. 2000.

[4] C.Y. Yeh and R. Zoughi, "A novel microwave method for detection of long surface cracks in metals", IEEE Trans. Instrum. Meas., Vol. 43, No. 5, pp. 719-725, Oct. 1994.

[5] A.M. Albishi, M.S. Boybay, and O. M. Ramahi, "Complementary split-ring resonator for crack detection in metallic surfaces”, IEEE Microw. Wireless Compon. Lett, vol. 22, no. 6, pp. 330-332, Jun. 2012.

[6] Yun, T. Lim, S. High-Q and miniaturized complementary split ring resonator-loaded substrate integrated waveguide microwave sensor for crack detection in metallic materials. Sens. Actuators A. Phys., Vol. 214, pp. 2530,2014

[7] A.K. Iyer and G.V. Eleftheriades, "Negative refractive index metamaterials supporting 2-D waves", in Proc. IEEEMTT Int. Microw. Symp, Seattle, WA, USA, Vol. 2, pp. 412-415, Jun. 2002.

[8] A.A. Oliner, "A periodic-structure negative-refractive-index medium without resonant elements", in Proc. IEEEAP-S USNC/URSI Nat. RadioSci Meeting, SanAntonio, TX, USA, p.41, Jun.2002.

[9] C. Caloz and T. Itoh, "Application of the transmission line theory of left-handed (LH) materials to the realization of a microstrip LH transmission line”, in Proc. IEEE-AP-S USNC/URSI Nat. Radio Sci. Meeting, SanAntonio, TX, USA, Vol. 2, pp. 412-415, Jun. 2002. 
[10] F. Martín, F. Falcone, J. Bonache, R. Marqués, and M. Sorolla, "Split ring resonator based left handed coplanar waveguide", Appl. Phys. Lett., Vol. 83, pp. 4652-4654, Dec. 2003.

[11] P.K. Singhal and Bimal Garg, "Design and Characterization of Compact Microstrip Patch Antenna Using "Split Ring” Shaped Metamaterial Structure", Vol. 2, No. 5, pp. 655-662, October 2012.

[12] F. Falcone, T. Lopetegi, J. D. Baena, R. Marqués, F. Martín, and M. Sorolla,"Effective negative- stop-band microstrip lines based on complementary split ring resonators", IEEE Microw. Wireless Compon. Lett, Vol. 14, No. 6, pp. 280-282, Jun. 2004.

[13] J.D. Baena, J. Bonache, F. Martín, R. Marqués, F. Falcone, T. Lopetegi, M.A.G. Laso, J. García, I. Gil, M. FloresPortillo, and M. Sorolla, "Equivalent circuit models for split ring resonators and complementary split rings resonators coupled to planar transmission lines", IEEE Trans. Microw. Theory Tech., Vol. 53, No. 4, pp. 14511461, Apr. 2005.

[14] R. Marqués, F. Martín, and M. Sorolla, "Metamaterials with Negative Parameters", Theory, Design and Microwave Applications. Hoboken, NJ, USA: Wiley, 2007.

[15] Jordi Naqui, Miguel Durán-Sindreu, Ferran Martín, "Modeling Split-Ring Resonator (SRR) and Complementary Split-Ring Resonator (CSRR) Loaded Transmission Lines Exhibiting Cross-Polarization Effects", IEEE Antennas and Wireless Propagation Letters, Vol. 12, 2013

[16] J.B. pendry, A.J. Holden, D.J. Robbins and W.J. Stewart, "Magnetism from conductors and enhanced nonlinear phenomena", 47(11): 2075-2084, Nov 1999.

[17] O Necibi, A Ferchichi, TP Vuong, A Gharsallah, "Miniaturized CSRR TAG Antennas for 60GHz Applications", Vol. 4, No. 1, pp. 64-74, Feburary 2014.

[18] Raoul O. Ouedraogo, Edward J. Rothwell, Alejandro R. Diaz, Kazuko Fuchi, Andrew Temme, "Miniaturization of Patch Antenna using a Metamaterial-inspired Technique", IEEE Transaction on Antennasand Propagation, Vol. 60, No. 5, May 2012.

[19] Smriti, Jaswinder Kaur, "Complementary Split Ring Resonators based Dual-Band Microstrip Antenna for WLAN Applications", International Journal of Advanced Reaserach in Computrer and Communication Engineering, Vol. 3, Issue 5, May 2014.

[20] Koon-Tae Kim, Jae-Hyeong Ko, Kyung Choi, Hyeong-Seok Kim, "Optimum Design of Wideband Bandpass Filter With CSRR-Loaded Transmission Line Using Evolution Strategy", IEEE Transactions on Magnetics, Vol. 48, No. 2, Feburary 2012

[21] Rajni and Anupma Marwaha, "Analysis of magnetic resonance in Metamaterial structure", COMSOL conference, 2011.

[22] Rajni, Gursharan Kaur, Amanpreet Kaur and Anupma Marwaha, "Investigation on Frequency Analysis of Metamaterial Structure", International conference Electronics Design Innovtion and Technologies, EDIT-2015, Vol-2, pp. 166-168, April 2015.

\section{BIOGRAPHIES OF AUTHORS}

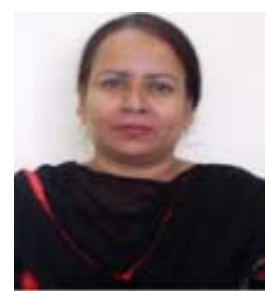

Rajni is currently Associate Professor at SBS StateTechnical Campus Ferozepur, India. She has completed her M.E. from NITTTR, Chandigarh, India and B.Tech from NIT, Kurukshetra India. She is pursuing her Ph.D. in metamaterial antennas. She has approx. 17 years of academic experience. She has authored a number of research papers in International journals, National and International conferences. Her areas of interest include Wireless communication and Antenna design.

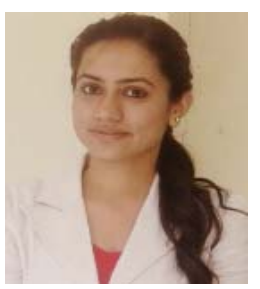

Amanpreet Kaur is currently pursuing M.Tech from SBS State Technical Campus, Ferozepur, India. She has completed B.Tech from PTU Jalandhar in 2013. Her area of interest include Antenna design

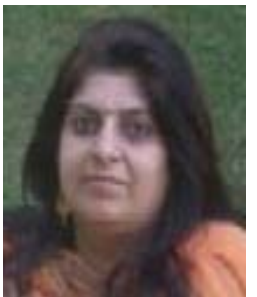

Dr Anupma Marwaha is currently Associate Professor at Sant Longowal Institute of Engg. \& Tech, Logowal (Sangrur). She has done her Ph.D from GNDU, Amritsar, M. Tech. from REC Kurukshetra (Now NIT, Kurukshetra), B.E from Punjab University, Chandigarh. She has 22 years of academic experiemce. She has authored 25 research papers in International and National Journals and 50 research papers in National and International conferences. She has supervised 02 $\mathrm{Ph} . \mathrm{D}$ Thesis and $10 \mathrm{M}$.Tech thesis and 04 are under progress. Her areas of interest include Electromagnetics, Microwave Comm, Wireless communication and Antenna Design.

IJECE Vol. 5, No. 5, October 2015 : $1012-1017$ 